\title{
Revolving-Field Polygon Technique for Performance Prediction of Single-Phase Induction Motors
}

\author{
Claus B. Rasmussen and T. J. E. Miller, Fellow, IEEE
}

\begin{abstract}
This paper presents a new analytical technique for improving the performance prediction of single-phase induction motors, especially capacitor motors. The technique uses the split-phase motor electrical equivalent circuit analysis together with electrical and magnetic parameters whose variation is computed from the equivalent balanced polyphase motor, so that the same magnetic circuit analysis can be used for both. (The term split-phase is used to cover motors operating from a single-phase supply but with the phase windings split into two orthogonal windings, one of which may have a capacitor in series with it during running or starting.) The technique accounts for the elliptical envelope of the magnetizing field vector and results in improved precision, since the three-phase electromagnetic model is considered to be more precise than the normal split-phase motor analysis. An important result is the computation of vector polygons of flux density for each section of the magnetic circuit, providing a better basis for core loss prediction. The double-frequency torque ripple is also obtained from the stator magnetomotive force and flux-density polygons. Three different electrical equivalent circuit methods for the split-phase motor (based respectively on the cross-field theory, forward- and backward-revolving fields, and symmetrical components) are evaluated to determine the method best suited for incorporating the variation of the circuit parameters from the polyphase magnetic circuit analysis, and it is discussed how the core losses can be included in these circuits to obtain the best overall performance prediction.
\end{abstract}

Index Terms-Induction motors, single-phase motors, unbalanced operation.

\section{INTRODUCTION}

$\mathbf{T}$ HE single-phase induction motor is widely used in low-power applications such as refrigerators and a variety of pumping applications, many of which run for long periods. Power levels range from subfractional to a few kilowatts, and energy conservation studies have identified this motor as having significant potential for savings in energy consumption. Fig. 1 shows an example of the type of motor analyzed. Against this background the efficiency of these small motors is an important design parameter [1], [2].

The theoretical basis of design calculations for both polyphase and split-phase induction motors is the electrical

Paper IPCSD 01-068, presented at the 2000 Industry Applications Society Annual Meeting, Rome, Italy, October 8-12, and approved for publication in the IEEE TRANSACTIONS ON INDUSTRY APPLICATIONS by the Electric Machines Committee of the IEEE Industry Applications Society. Manuscript submitted for review October 15, 2000 and released for publication July 1, 2003. This work was supported in part by the Danish Energy Agency.

C. B. Rasmussen is with Grundfos A/S, 8550 Bjerringbro, Denmark (e-mail: cbrasmussen@grundfos.com).

T. J. E. Miller is with the SPEED Laboratory, Department of Electronics and Electrical Engineering, University of Glasgow, Glasgow G12 8LT, U.K. (e-mail: t.miller@elec.gla.ac.uk).

Digital Object Identifier 10.1109/TIA.2003.816563

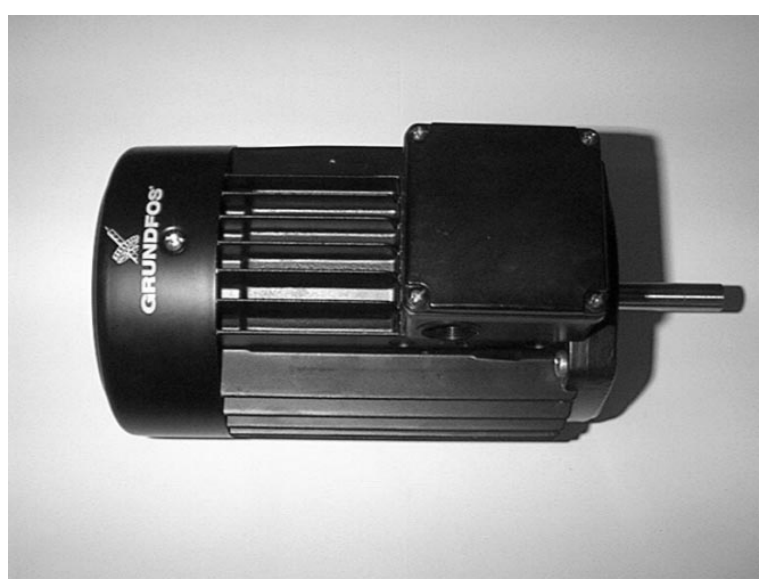

Fig. 1. Small induction motor of the type analyzed.

equivalent circuit [3]-[5]. In both cases the parameters of this circuit vary with slip, load, and voltage. Their computation is simpler in the polyphase motor because the flux is essentially constant and rotates at synchronous speed, whereas in the split-phase motor it varies cyclically and is visualized as having forward and backward revolving components. Since the flux variation in split-phase motors is "elliptical" it can be treated with reference to a variable-voltage calculation in the equivalent polyphase motor [6]. This is the basis for the method described in the paper.

Superimposed on the main flux is a set of harmonic variations caused by the effects of saturation, slotting, and skew [7]. These variations are themselves accompanied by induced rotor currents which do not participate in torque production but contribute significantly to the stray loss, and any method for estimating the stray loss must be built on a sound analysis of the main flux as described in the paper [6].

In polyphase motor analysis the core loss and stray loss are usually incorporated into the equivalent circuit by means of resistors connected, for example, in parallel with the magnetizing reactance or in series with the winding resistances. In single-phase motors the equivalent circuit has two sections, for example, one for the forward and one for the backward field, and it is not obvious how these losses should be apportioned between the two sections. Although the originators of the main analyses of the single-phase motor [8]-[14] recognized the possibility of including core losses via resistors in the equivalent circuit, they did not have the computing facilities necessary to solve these circuits when the resistors vary with operating conditions and, therefore, the core losses were often omitted in electrical performance calculations or lumped together with mechanical losses. 


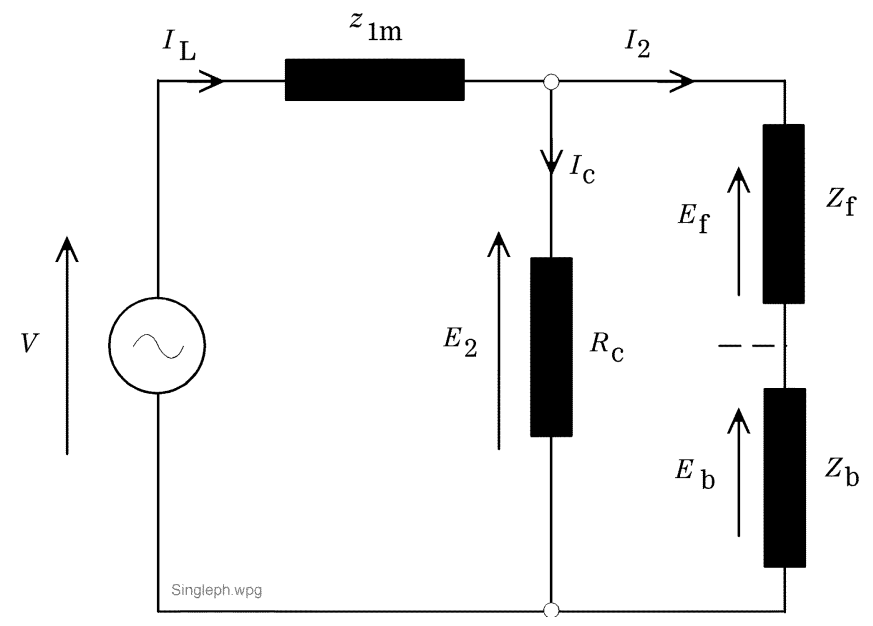

Fig. 2. Single-phase motor equivalent circuit including core loss.

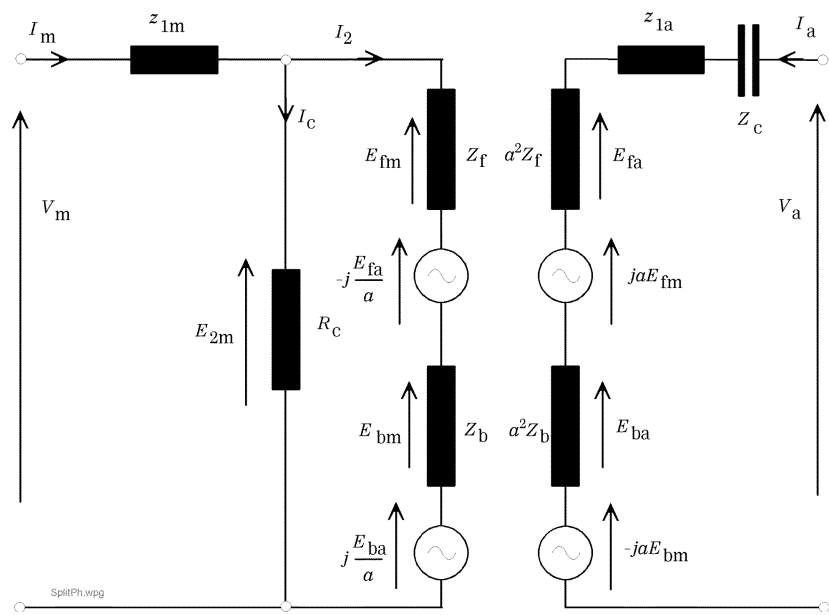

Fig. 3. Split-phase motor equivalent circuit based on forward- and backwardrevolving fields, including core loss.

The circuits described in this paper have variable core-loss resistors, with the losses divided between the two parts of the circuit according to physical principles described later. The circuits are solved iteratively by means of a computer program [15].

\section{THEORY}

\section{A. Equivalent-Circuit Models}

The equivalent-circuit models used in this paper are based on the classical models extended to include core-loss resistances [8]-[14]. Fig. 2 shows the pure single-phase model, Fig. 3 the forward- and backward-revolving-field model [14], and Fig. 4 the symmetrical components model [15]. The cross-field model shown in Fig. 5 is considerably more complex because it includes a tapped main winding [4], [10], [15], [16] and three core-loss resistances connected in parallel with the elements of the winding equivalent circuits that represent their respective flux linkages.

\section{B. Revolving-Field Polygon Technique}

When analyzing a split-phase motor, the technique starts by replacing the split-phase winding with an equivalent three-phase

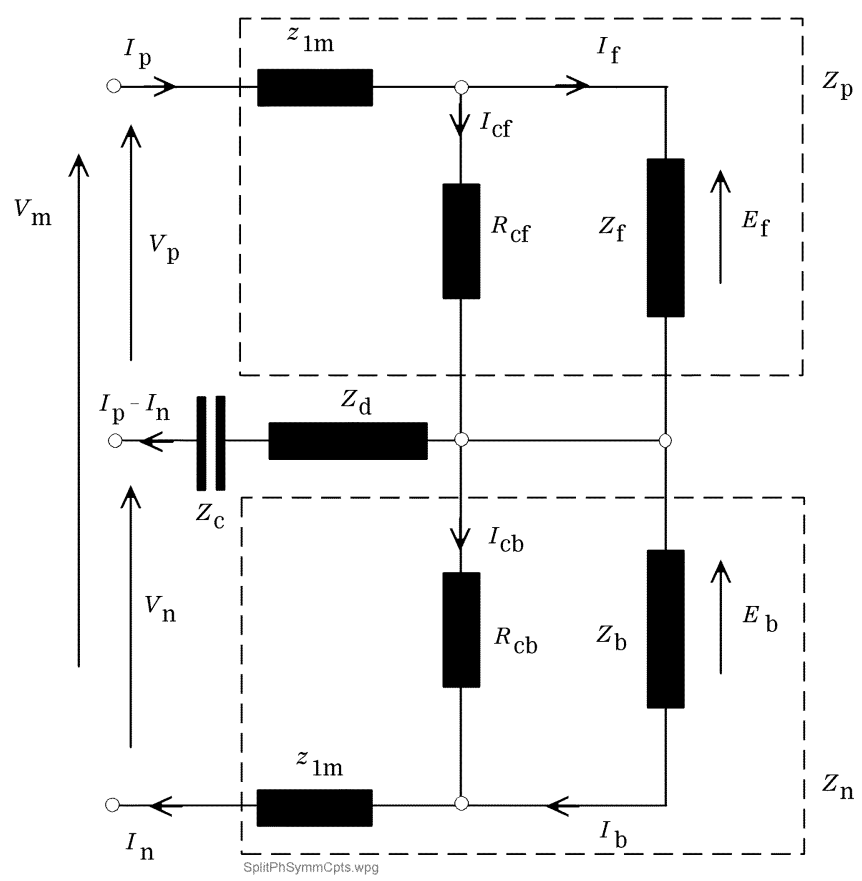

Fig. 4. Split-phase motor equivalent circuit based on symmetrical components, including core loss.

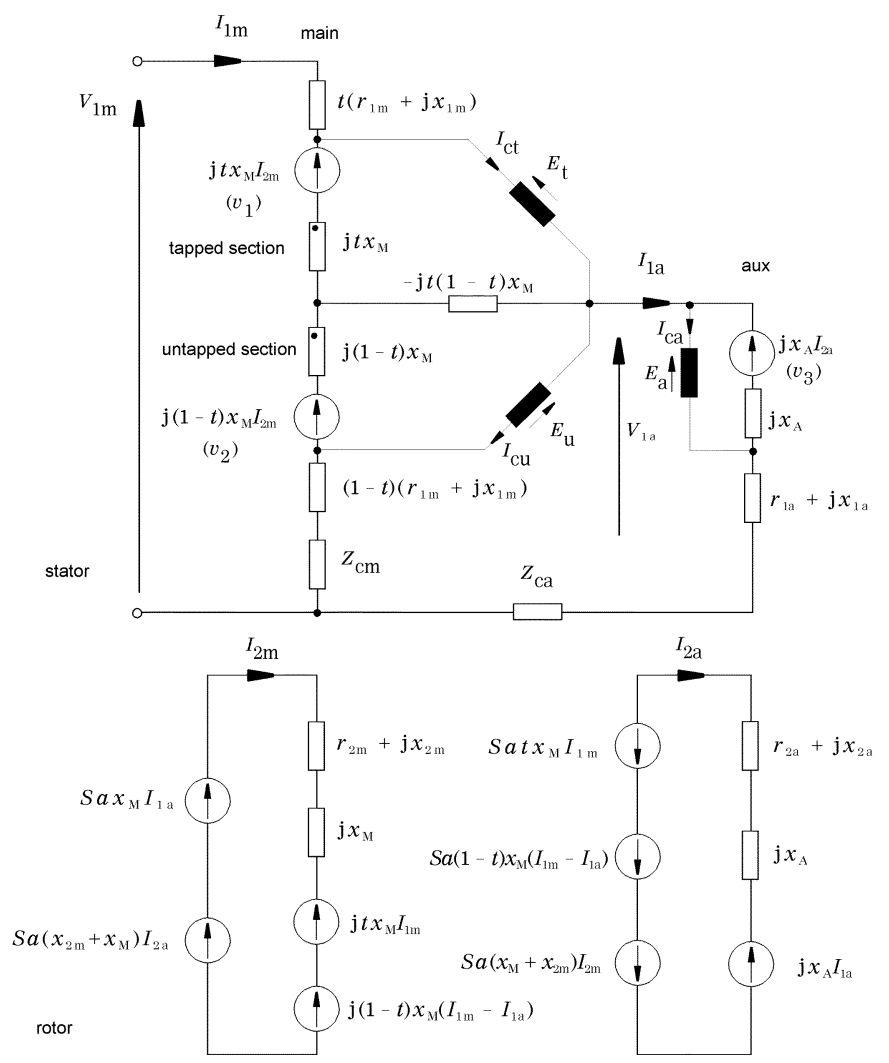

Fig. 5. Cross-field equivalent-circuit including a tapped main winding and three core-loss resistors [15], [16].

winding. The motor is then analyzed as a three-phase motor at no load, and the voltage is ranged to cover all saturation levels. The following parameters are logged: magnetizing magnetomotive force (MMF), magnetizing reactance $X_{\mathrm{m}}$, and values of peak flux density $B$ in every section of the magnetic circuit: 


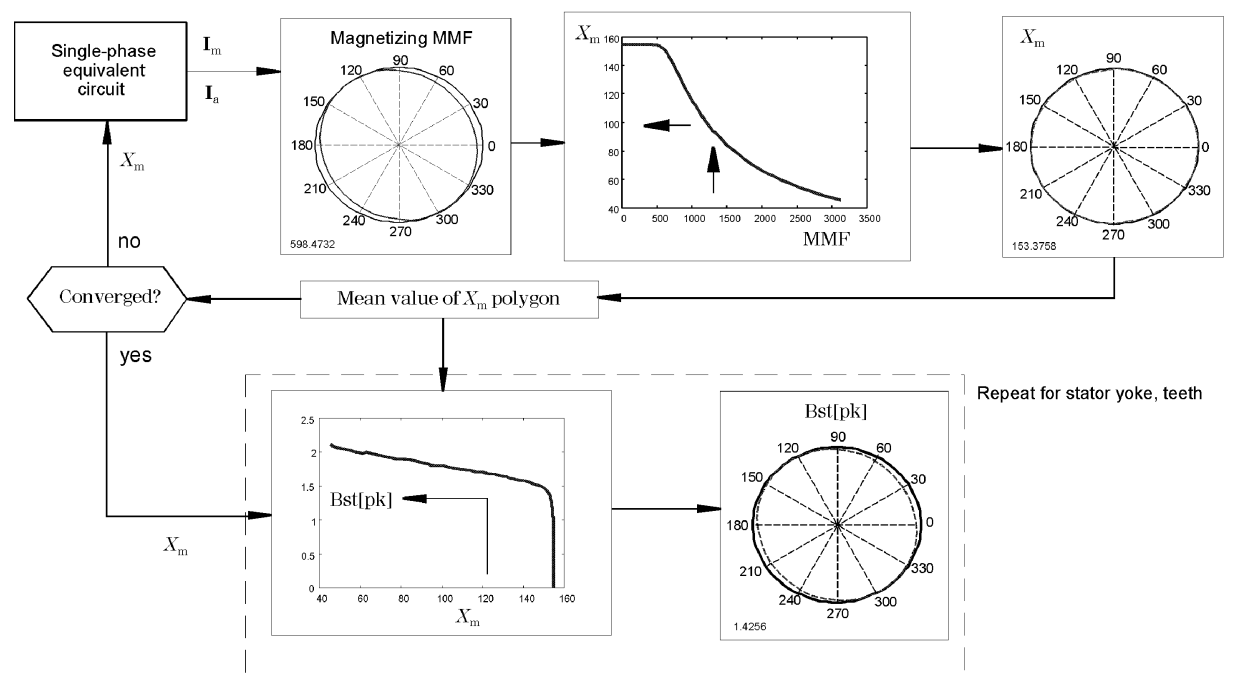

Fig. 6. Integration of three-phase and split-phase electric and magnetic analysis, by the revolving-field polygon technique.

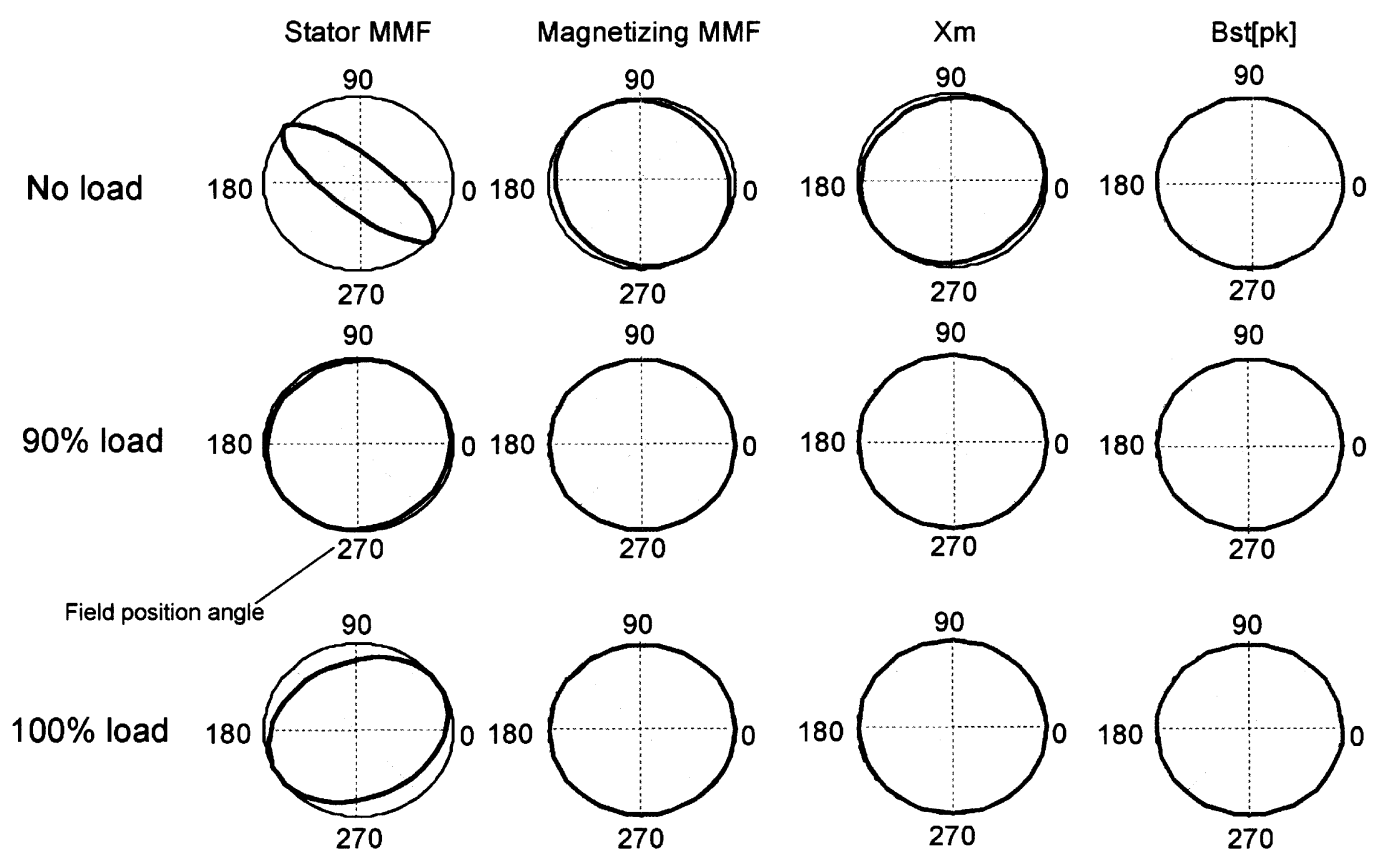

Fig. 7. Polygons obtained at three different load points for 470-W motor.

stator teeth and yoke; rotor teeth and yoke. The magnetizing $\mathrm{MMF}$ and $X_{\mathrm{m}}$ are used to determine the magnetizing reactance of the split-phase motor as shown in Fig. 6.

The procedure is iterative and starts with the split-phase magnetizing reactance taken from a standard magnetic circuit calculation. The procedure generates polygons (approximate ellipses) of the MMF and reactance values in a polar plot in which the magnitude is represented by the radius and the angle is the phase during one cycle at fundamental frequency. When the procedure has converged, the corresponding polygons of flux density in each section of the magnetic circuit are found by cross plotting from the polyphase ranging calculation.

The process described by Fig. 6 can be further interpreted graphically as in Fig. 7. The space vectors of flux density in each section of the magnetic circuit are related to the magnetizing MMF space vector via the magnetic equivalent circuit for an equivalent three-phase balanced machine which has the same geometry as the single-phase machine. If slotting and phase-belt effects are ignored, the three-phase machine has circular loci for both the magnetizing MMF and the flux, and its nonlinear magnetic equivalent circuit is used to determine the relationships between $X_{\mathrm{m}}$ and the peak flux densities in each section, taken over a range of voltage at no load. $X_{\mathrm{m}}$ is used because the saturated main field reactance in the cross-field model of the single-phase machine most closely represents the general magnetic state of the machine. The parameters stored with $X_{\mathrm{m}}$ from the voltage-ranging calculation are the flux densities and MMF drops for all sections of the magnetic circuit, and the total magnetizing MMF.

The voltage-range data from the three-phase motor are then linked to the split-phase equivalent circuit. The cross-field method was selected for this, since it operates with a main 
field reactance and a magnetizing current as in the three-phase equivalent circuit. The other two split-phase equivalent circuits operate with forward and backward components which make it more difficult to relate the magnetizing current and the main field reactance to the three-phase motor data.

The voltage-range data from the three-phase motor are applied to the cross-field split-phase equivalent circuit in the following steps.

1) Solve the cross-field circuit for a starting value of $X_{\mathrm{m}}$. This produces a revolving field polygon for the space vector of the magnetizing MMF, with a generally elliptical shape.

2) For each value of magnetizing MMF along the polygon, look up the corresponding value for the main field reactance of the equivalent three-phase machine. The result is a polygon for $X_{\mathrm{m}}$ representing its variation over one electrical period.

3) Determine the mean value of $X_{m}$ from the polygon and apply this in the cross-field circuit.

4) Repeat steps 1)-3) until the mean value of $X_{m}$ has converged to a steady value.

At this point the electrical quantities from the cross-field method are determined, and the flux densities for each section of the magnetic circuit are mapped from the final $X_{\mathrm{m}}$ polygon obtained in the voltage-ranging calculation; see Fig. 6.

\section{Core Losses}

The revolving-field polygon technique generates the time waveform of the flux density in each section of the magnetic circuit, permitting the core loss to be calculated using a modified Steinmetz equation of the form

$$
W_{\mathrm{Fe}}=C_{\mathrm{h}} \hat{B}^{n(\hat{B})}+C_{\mathrm{e}}\left|\frac{d B}{d t}\right|^{2}
$$

where $C_{\mathrm{h}}, C_{\mathrm{e}}$, and $n$ are coefficients determined from standard sine-wave loss curves; $n$ is an exponent of the order of 1.5-2.5 and $|d B / d t|^{2}$ represents the mean value of $(d B / d t)^{2}$ over one electrical cycle. The polygon of the space vector of flux density in each section of the magnetic circuit is used to find a representative $B$ value via a $B^{2}$ weighting, which is deduced from the form of (1) as a reasonable and simple means of representing the influence of flux-density variation on the core losses. The stray losses can be calculated by superimposing slot and phase-belt harmonics on the $B$ waveforms, but this process is beyond the scope of the present paper.

\section{Ripple Torque}

The revolving-field polygon technique can be used to determine the torque ripple taking into account the polygon shapes of the stator MMF and the motor flux; see Fig. 8.

The instantaneous torque is derived from the product of the back electromotive force (EMF) $N d \Phi / d t$ and the phase current $i$, divided by the speed, where $N$ is the number of turns per phase. The product $N i$ combined for all three phases is the stator MMF space vector. The flux/time derivative $d \Phi / d t$ will have the same polygon shape as the flux, and the highest derivative appears where the amplitude of the flux is highest, assuming

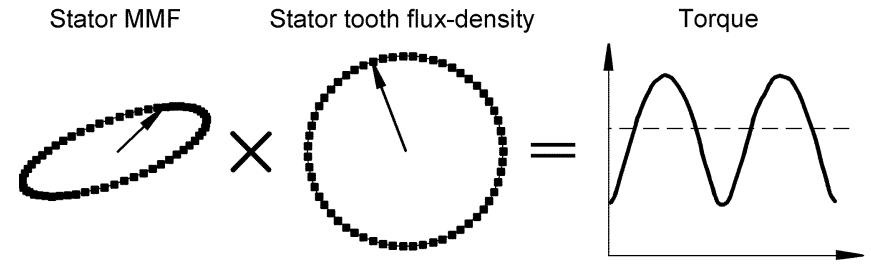

Fig. 8. Calculation of ripple torque.

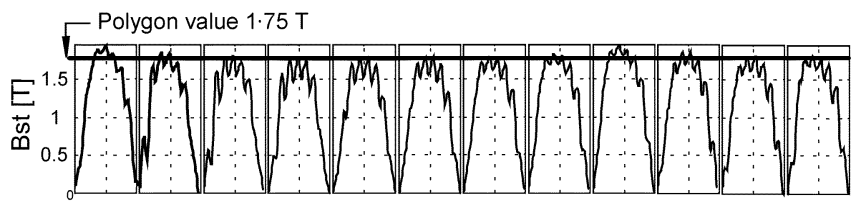

Fig. 9. Comparison of tooth flux densities obtained by finite-element calculation and the revolving-field polygon technique. 470-W two-pole motor at $100 \%$ load. Adjacent tooth flux-density waves.

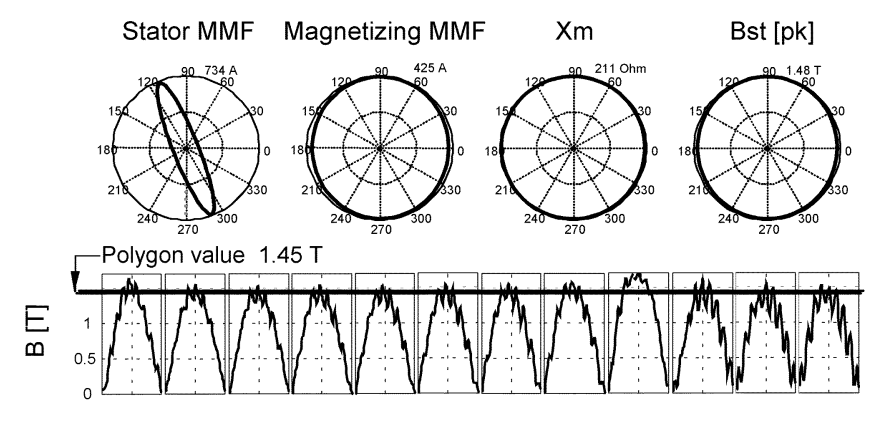

Fig. 10. Revolving-field polygons and finite-element tooth flux-density waveforms in 12 adjacent stator teeth at $66 \%$ voltage, no load. 470 -W two-pole $50-\mathrm{Hz}$ motor.

constant spatial flux distribution. Thus the torque waveform is obtained from a point-by-point multiplication of the stator MMF and tooth flux-density polygons. Finally, the mean torque obtained from the cross-field equivalent circuit calculation is used to scale the torque waveform over a complete electrical cycle.

\section{RESULTS}

Test results from this technique are shown in Fig. 7 for a two-pole split-phase motor at different speeds. The polygons show that the total stator MMF is much more elliptical than the magnetizing MMF, the magnetizing reactance $X_{\mathrm{m}}$, or the tooth flux-density space vectors. The near-circular loci of these last three parameters justify the revolving-field polygon technique.

To validate the flux polygon shape still further, a transient finite-element calculation was used to determine the time fluxdensity waves of the teeth. This result helps to identify the parameters which control the circularity of both the magnetizing MMF and the resulting flux polygons. Fig. 9 shows the finite-element tooth flux-density waves at full load.

Agreement between the finite-element method and the revolving-field polygon technique is good, considering that the finite-element result includes flux-density variations due to space harmonics associated with phase belts and slotting. These effects are not modeled in the polygon technique. 


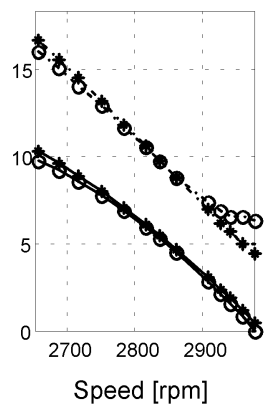

(a)

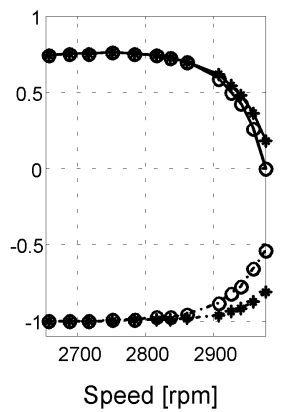

(b)

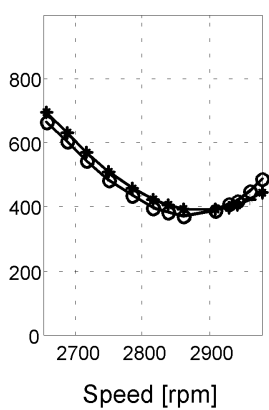

(c)

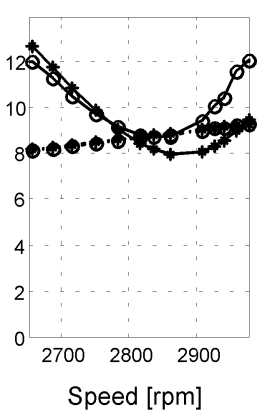

(d)

Fig. 11. Comparison of forward- and backward-rotating field equivalent-circuit model with test data. Split-phase motor with running capacitor, $2200 \mathrm{~W}$, two-pole, $50 \mathrm{~Hz}$. (a) Line current (A) and torque (N.m). (b) Efficiency and power factor. (c) Iron loss $W_{\mathrm{Fe}}$ plus stray loss $W_{\mathrm{SLL}}$ plus rotor copper loss $W_{\text {cuR }}$. (d) Main and auxiliary currents (A).

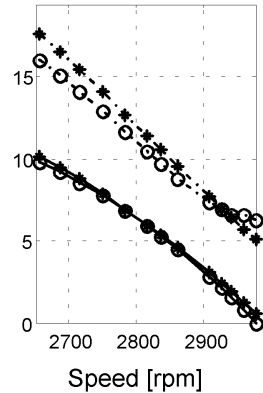

(a)

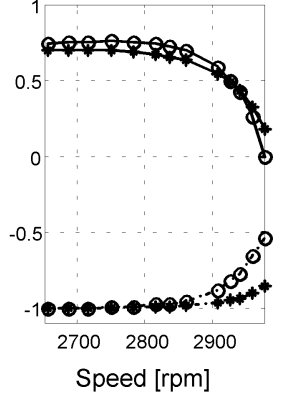

(b)

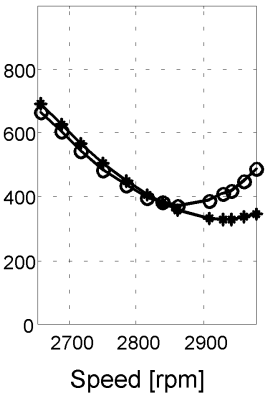

(c)

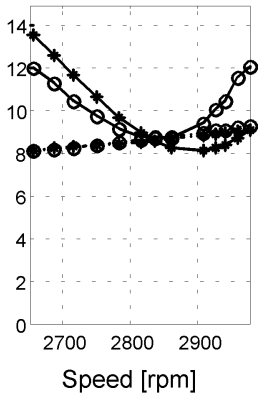

(d)

Fig. 12. Comparison of symmetrical-component equivalent-circuit model with test data. Motor is the same as for Fig. 11. (a) Line current (A) and torque (N.m). (b) Efficiency and power factor. (c) Iron loss $W_{\text {Fe }}$ plus stray loss $W_{\mathrm{SLL}}$ plus rotor copper loss $W_{\mathrm{CuR}}$. (d) Main and auxiliary currents (A).

To get an idea of the influence of saturation on the circularity of the flux polygons, a comparison with finite elements is made at reduced voltage as shown in Fig. 10.

The comparison at reduced voltage also shows good agreement with the finite-element results. The flux-density polygon at reduced voltage is circular, and it is concluded that saturation has little influence on the shape of the polygons of flux, flux density, and magnetizing MMF in a typical split-phase motor. The circularity is attributed to the relatively long time constant of the rotor compared with one electrical cycle. In other words, the cyclic variations in stator MMF are compensated and virtually cancelled out by opposite variations in the rotor MMF.

\section{A. Comparison of Split-Phase Equivalent-Circuit Models}

In order to show the quality of the methods the results are compared with standard measurements in the range 0\%-120\% load. Stray losses are added to the mechanical losses. The comparison includes line current, torque, efficiency, power factor (treated as negative for plotting purposes), main and auxiliary currents, and the sum: core + stray losses + rotor ohmic loss. The core losses are modeled by (1) with a weighting factor of 2 as explained earlier, and the stray loss is taken as $2 \%$ of the shaft power.

The temperature of the stator winding was set to the mean of the measured average winding temperature (obtained from resistance increase) during the whole test. The rotor temperature was assumed to be $20 \%$ higher than the stator winding temperature.

Figs. 11-13 show that the cross-field and the forward- and backward- components methods agree closely and provide the best agreement with measurements. Both methods lack load dependency at light load, probably because the magnetic circuit solver does not directly account for the actual elliptical shape of the fields in the split-phase motor. The symmetrical components method deviates from the other two methods, as a result of the different methods for including the core loss. All three methods give the same results when the core losses are excluded.

\section{B. Validation of the Revolving Field Polygon Technique by Comparison with Standard Test Data}

To validate the overall performance prediction, several comparisons were made with standard test data. One such comparison is shown in Fig. 14 for a 2200-W two-pole 50-Hz capacitor motor. Agreement between test and calculation is improved compared with Figs. 11-13. Similar comparison results were obtained for different motors at 470 and $2200 \mathrm{~W}$. The magnetic circuit calculation for the equivalent three-phase motor is described in [10].

\section{CONCLUSION}

A technique for improving performance prediction in splitphase induction motors has been presented, including theory 


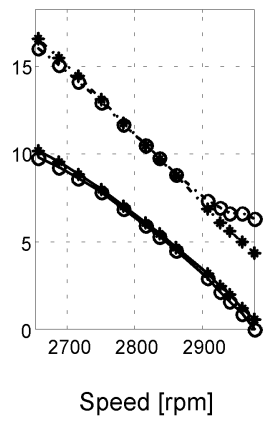

(a)

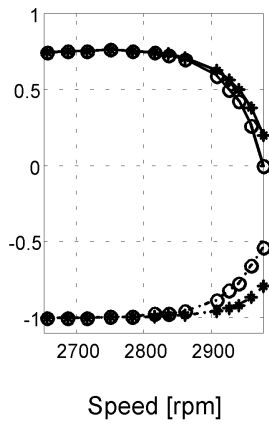

(b)

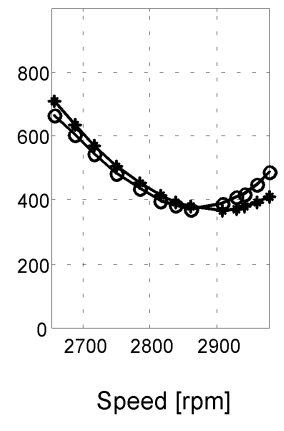

(c)

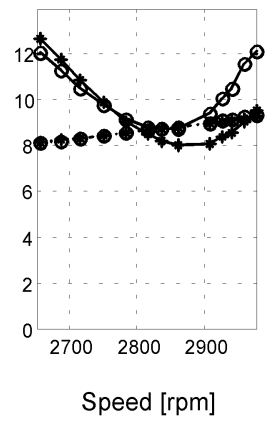

(d)

Fig. 13. Comparison of cross-field equivalent-circuit model with test data. Motor is the same as for Fig. 11. (a) Line current (A) and torque (N.m). (b) Efficiency and power factor. (c) Iron loss $W_{\mathrm{Fe}}$ plus stray loss $W_{\mathrm{SLL}}$ plus rotor copper loss $W_{\mathrm{CuR}}$. (d) Main and auxiliary currents (A).

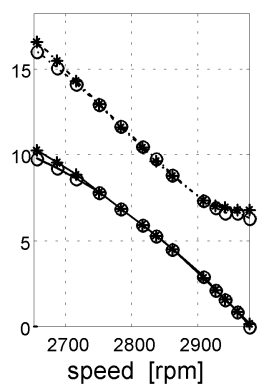

(a)

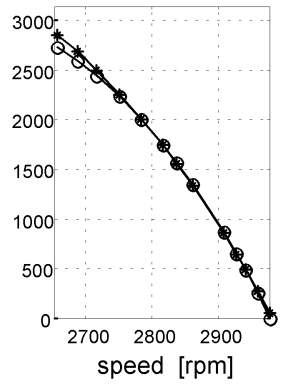

(e)

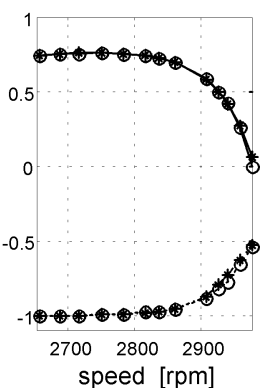

(b)

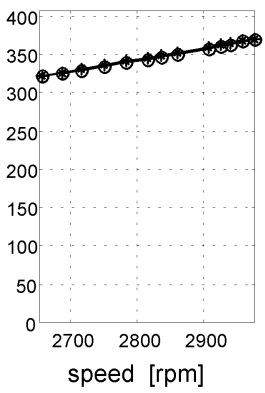

(f)

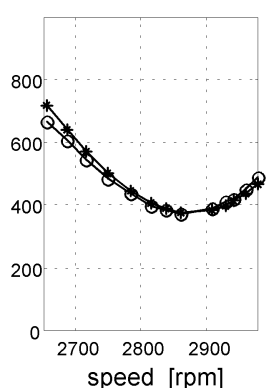

(c)

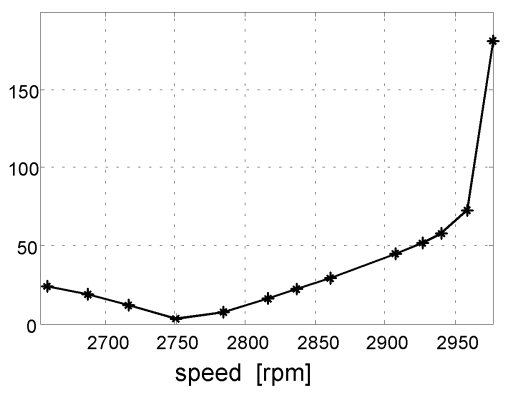

(g)

Fig. 14. Comparison of calculation and test for a 2200-W capacitor motor (stars: calculation; circles: test).

and experimental results from a selection of motors. The technique is based on the elliptical locus of the space vectors of stator MMF, magnetizing MMF, and air-gap flux, and a corresponding locus constructed for the magnetizing reactance.

The varying saturated magnetizing reactance is determined from a voltage-ranging calculation in the equivalent balanced three-phase machine. The technique therefore takes account of both the elliptical variation of the stator MMF and the effect of saturation on the magnetizing reactance and main flux. From a practical point of view it has the advantage of using a common magnetic circuit analysis for both the polyphase and split-phase machines. The split-phase motor analysis is improved as a result of the greater precision in the polyphase electromagnetic model, particularly in relation to the calculation of the air-gap flux-density waveform including saturation harmonics, [6].

It is shown that the loci of the space vectors of magnetizing MMF, air-gap flux, and tooth and yoke flux densities are much less elliptical than the locus of the space vector of total stator MMF. This is attributed to the long rotor time constant com- pared with one electrical cycle, such that induced rotor currents effectively damp out the variations in total stator MMF.

The technique improves the basis of the core loss calculation in the split-phase motor in two main ways. First, it provides a graphical visualization by means of polygons representing the variation of flux densities through one cycle, which show the degree of "ellipticity" in the various field components. Secondly, the core losses developed from the modified Steinmetz equation are incorporated in the main variants of the equivalent-circuit model based on cross-field, forwardand backward-revolving fields, and symmetrical components. Comparison with test data brings out the differences between these theoretical models, and it is shown that the cross-field model and the forward- and backward-revolving-field model produce somewhat better results than the symmetrical component model.

The technique also produces the waveform of the double-frequency torque ripple directly from the interaction of the stator MMF polygon and the main flux polygon. 
Comparison with test data for a $2200-\mathrm{W}$ capacitor motor shows an improvement for the revolving-field polygon technique over the standard equivalent-circuit models. Similar results have been obtained with 470- and 1100-W motors.

It is perhaps interesting to note that the solution of the equivalent-circuit models incorporating variable core-loss resistances requires an iterative technique far beyond the computational capability of the original developers of these models in the 1920s-1950s, even though the concepts would have been very recognizable by them. However, the revolving-field polygon technique and the validation by transient finite elements are essentially "computer-age" methods without parallel in the original literature.

\section{ACKNOWLEDGMENT}

The authors thank their colleagues at Grundfos A/s, Bjerringbro, Denmark; M. McGilp; and the SPEED Consortium.

\section{REFERENCES}

[1] Draft Standard Test Procedure for Single-Phase Induction Motors, IEEE P114/D1.2, July 28, 1998.

[2] IEEE Guide: Procedures for Testing Single-Phase and Polyphase Induction Motors for Use in Hermetic Compressors, IEEE Std. 839-1986.

[3] C. G. Veinott and J. E. Martin, Fractional and Subfractional Horsepower Electric Motors, 4th ed. New York: McGraw-Hill, 1992.

[4] C. G. Veinott, Theory and Design of Small Induction Motors. New York: McGraw-Hill, 1959.

[5] A. E. Fitzgerald and C. Kingsley Jr., Electric Machinery, 2nd ed. New York: McGraw-Hill, 1961.

[6] D. M. Ionel, M. V. Cistelecan, T. J. E. Miller, and M. I. McGilp, "A new analytical method for the computation of airgap reactances in 3-phase induction motors," in Conf. Rec. IEEE-IAS Annu. Meeting, St. Louis, MO, Oct. 12-15, 1998, pp. 65-72.

[7] B. Heller and V. Hamata, Harmonic Field Effects in Induction Machines. Amsterdam, The Netherlands: Elsevier, 1977.

[8] W. J. Morrill, "The revolving-field theory of the capacitor motor," Trans. AIEE, pp. 614-632, Apr. 1929.

[9] P. H. Trickey, "Performance calculations on capacitor motors," Trans. AIEE, vol. 60, pp. 73-76, Feb. 1941.

[10] A. F. Puchstein and T. C. Lloyd, "The cross-field theory of the capacitor motor," Trans. AIEE, pp. 58-63, Feb. 1942.
[11] P. H. Trickey, "Capacitor motor performance calculations by the crossfield theory," Trans. AIEE, pp. 1547-1553, Feb. 1957.

[12] W. V. Lyon and C. Kingsley, "Analysis of unsymmetrical machines," Trans. AIEE, pp. 471-476, May 1936.

[13] F. W. Suhr, "Symmetrical components as applied to the single-phase induction motor," Trans. AIEE, vol. 64, pp. 651-655, Sept. 1945.

[14] T. J. E. Miller, J. H. Gliemann, C. B. Rasmussen, and D. M. Ionel, "Analysis of a tapped-winding capacitor motor," in Proc. ICEM'98, vol. I, Istanbul, Turkey, Sept. 2-4, 1998, pp. 581-585.

[15] T. J. E. Miller, PC-IMD User's Manual, Version 2.5. Glasgow, U.K.: SPEED Laboratory, Dept. Electron. Elect. Eng., Univ. Glasgow, June 1999.

[16] C. B. Rasmussen and T. J. E. Miller, "Extended cross-field theory of the tapped-winding capacitor motor, including iron loss and alternate connections," in Conf. Rec. IEEE-IAS Annu. Meeting, vol. 4, Chicago, IL, 2001, pp. 2275-2279.

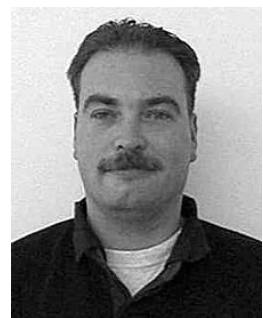

Claus B. Rasmussen received the M.S.E.E. and $\mathrm{Ph} . \mathrm{D}$. degrees in electrical engineering from Aalborg University, Aalborg East, Denmark, in 1993 and 1997, respectively.

For nine moths, he was an Associate Professor at Aalborg University. In 1997, he joined Grundfos A/S. Bjerringbro, Denmark, as a Development Engineer in the Motor Engineering Department with a focus on modeling and design of induction motors. He is currently a Senior Development Engineer at Grundfos.

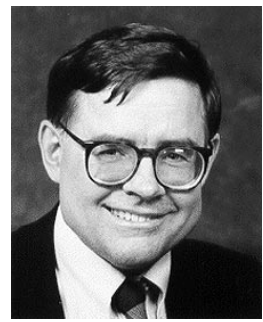

T. J. E. Miller (M'74-SM'82-F'96) is a native of Wigan, U.K. He received the B.Sc. degree from the University of Glasgow, Glasgow, U.K., and the Ph.D. degree from the University of Leeds, Leeds, U.K.

$\mathrm{He}$ is Professor of Electrical Power Engineering and founder and Director of the SPEED Consortium at the University of Glasgow, Glasgow, U.K. He is the author of over 100 publications in the fields of motors, drives, power systems, and power electronics, including seven books. From 1979 to 1986, he was an Electrical Engineer and Program Manager at GE Research and Development, Schenectady, NY, and his industrial experience includes periods with GEC (UK), British Gas, International Research and Development, and a student apprenticeship with Tube Investments Ltd.

Prof. Miller is a Fellow of the Institution of Electrical Engineers, U.K. 